\title{
Mesoporous $\mathrm{MgTa}_{2} \mathrm{O}_{6}$ thin films with enhanced photocatalytic activity: On the interplay between crystallinity and mesostructure
}

\author{
Jin-Ming Wu ${ }^{1}$, Igor Djerdj ${ }^{2}$, Till von Graberg ${ }^{3}$ and Bernd M. Smarsly ${ }^{* 3}$
}

\section{Full Research Paper}

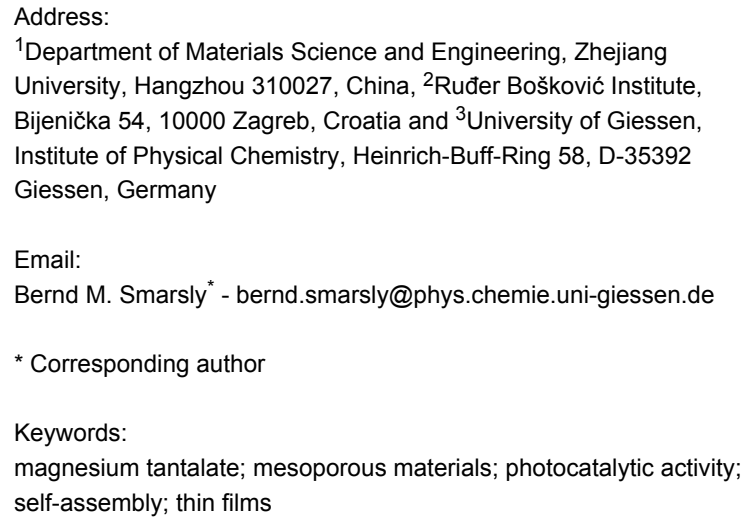

Beilstein J. Nanotechnol. 2012, 3, 123-133.

doi:10.3762/bjnano.3.13

Received: 10 September 2011

Accepted: 31 January 2012

Published: 13 February 2012

This article is part of the Thematic Series "Micro- and mesoporous solids: From science to application".

Guest Editor: J. J. Schneider

(C) 2012 Wu et al; licensee Beilstein-Institut. License and terms: see end of document.

\begin{abstract}
Ordered mesoporous, crystalline $\mathrm{MgTa}_{2} \mathrm{O}_{6}$ thin films with a mesoscopic nanoarchitecture were synthesized by evaporation-induced self-assembly (EISA) in combination with a sol-gel procedure. Utilization of novel templates, namely the block copolymers KLE

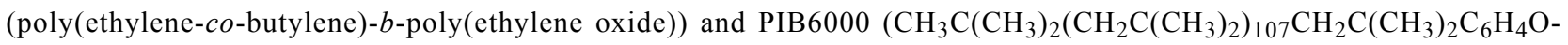
$\left.\left(\mathrm{CH}_{2} \mathrm{CH}_{2} \mathrm{O}\right)_{100} \mathrm{H}\right)$, was the key to achieving a stable ordered mesoporous structure even upon crystallization of $\mathrm{MgTa}_{2} \mathrm{O}_{6}$ within the mesopore walls. The effect of the calcination temperature on the ability of the mesoporous films to assist the photodegradation of rhodamine $\mathrm{B}$ in water was studied. As a result, two maxima in the photocatalytic activity were identified in the calcination temperature range of $550-850{ }^{\circ} \mathrm{C}$, peaking at $700{ }^{\circ} \mathrm{C}$ and $790{ }^{\circ} \mathrm{C}$, and the origin of this was investigated by using temperature-dependent $\mathrm{X}$-ray scattering. Optimal activity was obtained when the mesoporous film was heated to $790{ }^{\circ} \mathrm{C}$; at this temperature, crystallinity was significantly high, with $\mathrm{MgTa}_{2} \mathrm{O}_{6}$ nanocrystals of $1.6 \mathrm{~nm}$ in size (averaged over all reflections), and an ordered mesoporous structure was maintained. When considering the turnover frequency of such photocatalysts, the optimized activity of the present nanoarchitectured $\mathrm{MgTa}_{2} \mathrm{O}_{6}$ thin film was ca. four times that of analogous anatase $\mathrm{TiO}_{2}$ films with ordered mesopores. Our study demonstrated that high crystallinity and well-developed mesoporosity have to be achieved in order to optimize the physicochemical performance of mesoporous metal-oxide films.
\end{abstract}

\section{Introduction}

Because of its excellent microwave dielectric properties, $\mathrm{MgTa}_{2} \mathrm{O}_{6}$ is one of the ternary oxides that have been well studied for application as dielectric resonators operating at microwave frequencies [1-9]. In the form of thin films, it is also considered to be one of the most promising candidates for use in polarizers in optical communications and other optical 
devices [5]. The traditional ceramic method of synthesizing $\mathrm{MgTa}_{2} \mathrm{O}_{6}$, i.e., solid-state reaction, requires high temperatures of $1200-1400{ }^{\circ} \mathrm{C}$, which produces coarse grains and an inhomogeneous composition [6-8]. Crystalline $\mathrm{MgTa}_{2} \mathrm{O}_{6}$ powders were fabricated at $850{ }^{\circ} \mathrm{C}$ by a molten-salt method and at $550{ }^{\circ} \mathrm{C}$ by a wet-chemical approach [9]. Thin films containing mainly $\mathrm{MgTa}_{2} \mathrm{O}_{6}$ and $\mathrm{Mg}_{4} \mathrm{Ta}_{2} \mathrm{O}_{9}$ phases can be formed by reactions between $\mathrm{MgO}(001)$ substrates and $\mathrm{Ta}-\mathrm{O}$ vapors, which are produced by electron-beam evaporation of a $\mathrm{Ta}_{2} \mathrm{O}_{5}$ powder target in a high-vacuum system, at temperatures of 700-1000 ${ }^{\circ} \mathrm{C}$ [5].

In 1998, Kato and Kudo reported that $\mathrm{MgTa}_{2} \mathrm{O}_{6}$ that had been synthesized by calcination of mixtures of $\mathrm{Ta}_{2} \mathrm{O}_{5}$ and $\mathrm{MgCO}_{3}$ showed photocatalytic water-decomposition activity without cocatalysts [10]. Due to the inherent coarse-grain structure of $\mathrm{MgTa}_{2} \mathrm{O}_{6}$ powders fabricated by the solid-state reaction, their photocatalytic activity is quite low. With the help of a block polymer P123, a Mg-Ta oxide powder with highly ordered mesopores was previously synthesized [11]. After removal of the P123 template by washing in water, the wormholelike microporous $\mathrm{MgTa}_{2} \mathrm{O}_{6}$ powder, though amorphous, showed enhanced water-decomposition activity when compared to the crystalline $\mathrm{MgTa}_{2} \mathrm{O}_{6}$ prepared by a solid-state reaction. The high activity is ascribed to the thin walls $(2.8 \mathrm{~nm})$ separating the mesopores, as the excited electrons and holes only have to travel a short distance to the surface [11]. The use of photocatalysts in the form of thin films avoids the laborious recycling procedure, and this has promoted the development of high-efficiency $\mathrm{MgTa}_{2} \mathrm{O}_{6}$ thin films. One can expect enhanced photocatalytic activity from $\mathrm{MgTa}_{2} \mathrm{O}_{6}$ thin films with well-crystallized nanocrystallites and ordered mesopores, which guarantee the photocatalyst access to the target molecules and also possess a high specific surface area. Unfortunately, because of the high crystallization temperature and low decomposition temperature of most commercially available templates, the fabrication of ordered mesoporous $\mathrm{MgTa}_{2} \mathrm{O}_{6}$ thin films with crystallized walls remains a complex task, and hence detailed photocatalyticactivity studies of such films are scarce.

In particular, suitable well-defined mesoscopic, photocatalytically active metal oxides would be ideal materials for a case study to address the importance of high crystallinity coupled with a well-developed mesostructure. It has been often stated that the performance of mesoporous metal oxides requires both features to be optimized at the same time, but to the best of our knowledge no systematic study has been performed in the field of photocatalysis.

Various oxides with high crystallization temperatures have only recently been synthesized successfully in the form of highly ordered mesoporous thin films, thanks to novel templates such as poly(ethylene-co-butylene)- $b$-poly(ethylene oxide), "KLE" (Kraton Liquid -block-poly(ethylene oxide)). The KLE template is capable of forming relatively large mesopores and thick walls, and at the same time possesses a high decomposition temperature of up to $400{ }^{\circ} \mathrm{C}$, which facilitates preservation of the ordered mesoporous structure during heating to a high crystallization temperature [12-14]. This work reports the synthesis and photocatalytic characterization of crystallized, mesoporous $\mathrm{MgTa}_{2} \mathrm{O}_{6}$ thin films, obtained through an evaporation-induced self-assembly (EISA) approach, with the help of the KLE template. The photocatalytic activity of the nanoarchitectured $\mathrm{MgTa}_{2} \mathrm{O}_{6}$ thin film was compared both to that achieved by using the BASF Pluronic F127 (block copolymer $\mathrm{EO}_{106}-\mathrm{PO}_{70}-\mathrm{EO}_{106}$ ), which forms larger mesopores compared to most other commercially available templates, and to a previously reported type of anatase $\mathrm{TiO}_{2}$ thin film with ordered mesopores, examples of which are widely used as photocatalysts $[15,16]$. Recently, a further class of block copolymers with advanced templating properties was introduced, namely poly(isobutylene)- $b$-poly(ethylene oxide) $[14,17]$. Here, we also used such a polymer, namely "PIB6000", $\mathrm{CH}_{3} \mathrm{C}$ $\left(\mathrm{CH}_{3}\right)_{2}\left(\mathrm{CH}_{2} \mathrm{C}\left(\mathrm{CH}_{3}\right)_{2}\right)_{107} \mathrm{CH}_{2} \mathrm{C}\left(\mathrm{CH}_{3}\right)_{2} \mathrm{C}_{6} \mathrm{H}_{4} \mathrm{O}\left(\mathrm{CH}_{2} \mathrm{CH}_{2} \mathrm{O}\right)_{100} \mathrm{H}$, see [17], as an additional structure-directing agent.

As a main motivation, our study addressed the influence of the heat-treatment temperature (i.e., crystallite size) on the photocatalytic activity. Thereby, the influence of the crystallite size and mesostructural organization on the photocatalytic activity was systematically investigated by using dye degradation as a qualitative measure.

\section{Results and Discussion \\ Film characterization}

In the following, we focus on mesoporous $\mathrm{MgTa}_{2} \mathrm{O}_{6}$ films templated by the KLE block copolymer. PIB6000 generates films with very similar mesopore structure and crystallinity, with only the average lateral size of the mesopores (ca. $20 \mathrm{~nm}$ ) being larger than in the case of KLE template films (ca. $15 \mathrm{~nm}$ ). Since the mesopore structure (spherical mesopores) and also photocatalytical activity of these films are very similar, in the following, mainly KLE-templated films are discussed. Additional results for PIB6000-templated mesoporous films are presented in Supporting Information File 1.

Both the mesoporous and the nonporous (nontemplated) films show distinct X-ray diffraction (XRD) reflections corresponding to a tri-rutile structure $\mathrm{MgTa}_{2} \mathrm{O}_{6}$ (JCPDS card 32-0631), only after calcination at temperatures beyond $760{ }^{\circ} \mathrm{C}$, as illustrated in Figure 1. The crystallinity of $\mathrm{MgTa}_{2} \mathrm{O}_{6}$ in the KLE-templated mesoporous film increased with increasing 

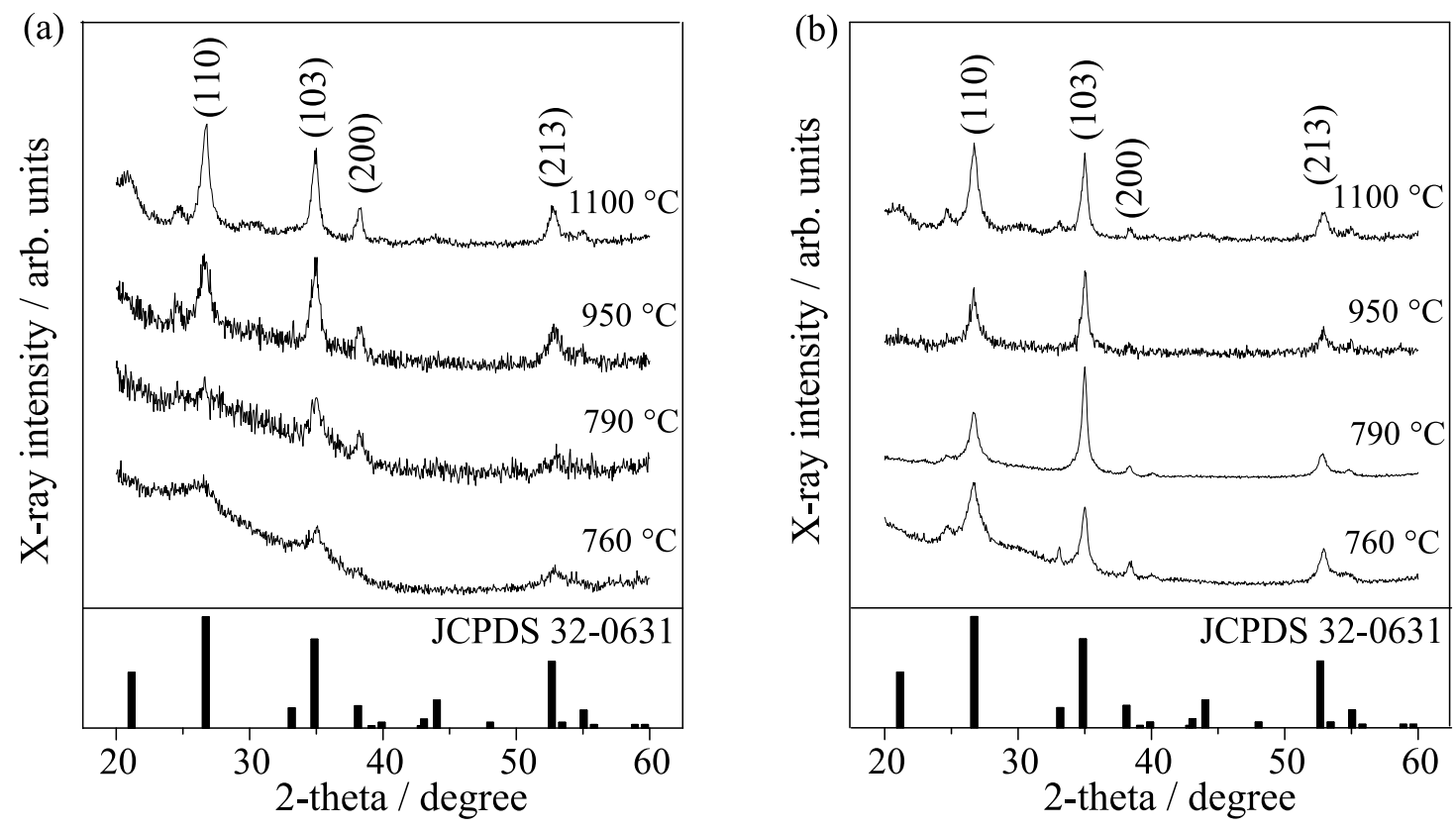

Figure 1: XRD patterns of (a) the KLE-templated mesoporous and (b) the nonporous $\mathrm{MgTa}_{2} \mathrm{O}_{6}$ thin film after thermal treatment at various temperatures.

calcination temperature from 760 up to $1100{ }^{\circ} \mathrm{C}$. The average grain size, which was estimated by applying the Rietveld refinement, is shown in Figure 2 as a function of the calcination temperature for both mesoporous and nonporous films. Owing to the lower overall crystallinity of the investigated material and a high background in some of the analyzed XRD patterns, the microstrain part in the size-microstrain procedure within the Rietveld refinement was not refined and was kept to the instrumental values determined by the crystalline standard. The standard was also used for the deconvolution of the instrumentalbroadening contribution. Since the initial refinement gave rather high disagreement between the experimental and calculated curves, particularly in the [103] direction, an anisotropic broadening with a larger crystallite size along the [103] direction was assumed. Accordingly, the difference curves were then smooth and all refinements were satisfactory. In Figure 2, vertical error bars represent the distribution interval of crystallite sizes for all reflections, and therefore the error interval is actually a measure of crystal anisotropy. It is obvious that the nonporous crystallites appear with a larger anisotropy (larger grains in [103] direction) compared to their mesoporous counterparts. When the calcination temperature was increased from 760 to $1100{ }^{\circ} \mathrm{C}$ the grain size of $\mathrm{MgTa}_{2} \mathrm{O}_{6}$ in the mesoporous film showed a gradual increase from 1.1 to $9.4 \mathrm{~nm}$. When both films were heated to the same temperature of 760 and $790{ }^{\circ} \mathrm{C}$, the crystallinity of $\mathrm{MgTa}_{2} \mathrm{O}_{6}$ in the nonporous film was more pronounced than in the mesoporous one, which can be attrib- uted to the retarding effect of the template and the mesopores on the grain growth.

Grain growth of $\mathrm{MgTa}_{2} \mathrm{O}_{6}$ in the nontemplated film with increasing calcination temperature from 760 up to $1100{ }^{\circ} \mathrm{C}$ was

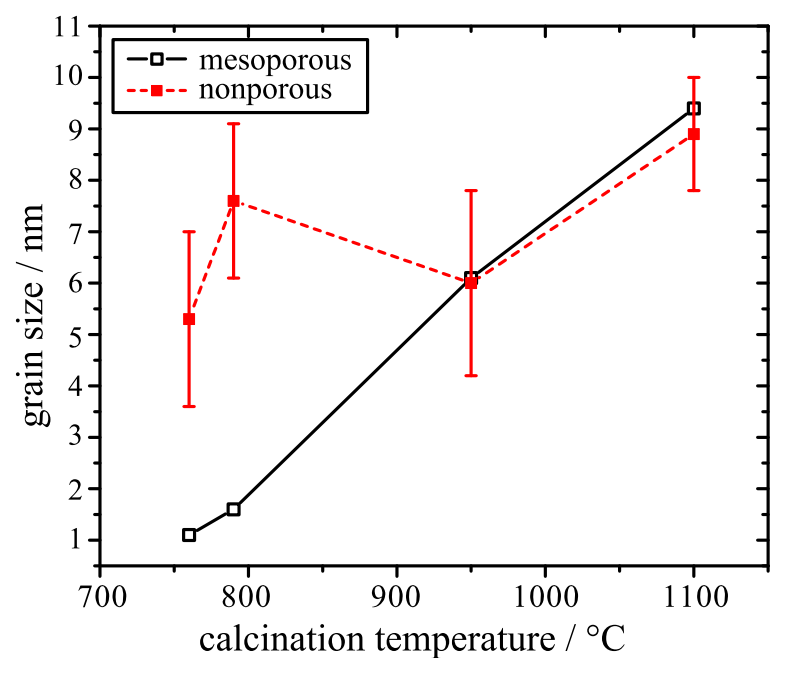

Figure 2: Average grain size and its standard deviation as a measure of anisotropy of $\mathrm{MgTa}_{2} \mathrm{O}_{6}$ in the mesoporous KLE-templated and nonporous films, as a function of the calcination temperature. 
not so conspicuous. The grain size only increased from 5.3 to $8.9 \mathrm{~nm}$.

Figure 3 shows the SEM surface morphology of the $\mathrm{MgTa}_{2} \mathrm{O}_{6}$ thin film subjected to various calcination temperatures. The EISA procedure achieved a crack-free surface with randomly distributed micrometer-sized round concaves, while the film as a whole consisted of highly ordered mesopores. The dual nanoarchitecture remained almost unchanged upon heating to $760{ }^{\circ} \mathrm{C}$, with crystallized $\mathrm{MgTa}_{2} \mathrm{O}_{6}$ appearing within the walls. After being heated to the highest temperature available $\left(1100{ }^{\circ} \mathrm{C}\right)$, conspicuous cracks appeared within the round concaves and the ordered mesopores decayed to a wormlike state. However, the microstructure was still preserved, and most thermally induced cracks were restricted to each concave, that is, they did not coalesce or propagate throughout the film upon heating to $1100{ }^{\circ} \mathrm{C}$. At this temperature, well-crystallized $\mathrm{MgTa}_{2} \mathrm{O}_{6}$ walls were obtained, as seen by XRD.

Figure 4 illustrates the AFM surface morphology of the $\mathrm{MgTa}_{2} \mathrm{O}_{6}$ film after calcination at $760{ }^{\circ} \mathrm{C}$, which is in agreement with the SEM observation. The corresponding height profile obtained from the AFM image suggests that the depth of the randomly distributed round concaves was ca. $60 \mathrm{~nm}$. The film thickness was estimated to be ca. $200 \mathrm{~nm}$; therefore, the ordered mesoporous $\mathrm{MgTa}_{2} \mathrm{O}_{6}$ film thoroughly covered the $\mathrm{Si}$ substrate. The distance between two neighboring mesopores remained constant at ca. $22 \mathrm{~nm}$ after calcination at $760{ }^{\circ} \mathrm{C}$. The ordered mesoporous structure was further confirmed by the TEM morphology of flakes scratched off from the $\mathrm{MgTa}_{2} \mathrm{O}_{6}$ film before and after heating at $760^{\circ} \mathrm{C}$, as indicated in Figure 5 . From such TEM images a spherical mesopore shape was inferred with an average mesopore diameter of ca. $15 \mathrm{~nm}$. TEM images of PIB6000-templated films are shown in Supporting Information File 1 (Figure S6).

Figure 6 shows the SAXS patterns (measured in symmetric reflection with a 1-D detector) of the mesoporous $\mathrm{MgTa}_{2} \mathrm{O}_{6}$ film after calcination at various temperatures. The diffuse SAXS pattern does not allow for an unambiguous determination of the pore morphology. Taking into account previous studies on KLE as a template and the TEM images, the SAXS data can be interpreted in terms of spherical mesopores, although fcc, bcc and hep structures cannot be distinguished. The scattering maxima are characteristic of ordered mesopores, being assigned as the (110) reflection of a distorted bcc mesoporous structure, and became diffuse as the calcination temperature increased to $760{ }^{\circ} \mathrm{C}$, i.e., the onset of crystallization temperature. However, the SAXS scattering maxima can still be discerned after calcination up to $1000{ }^{\circ} \mathrm{C}$. Therefore, the present ordered mesoporous $\mathrm{MgTa}_{2} \mathrm{O}_{6}$ film possessed a relatively high
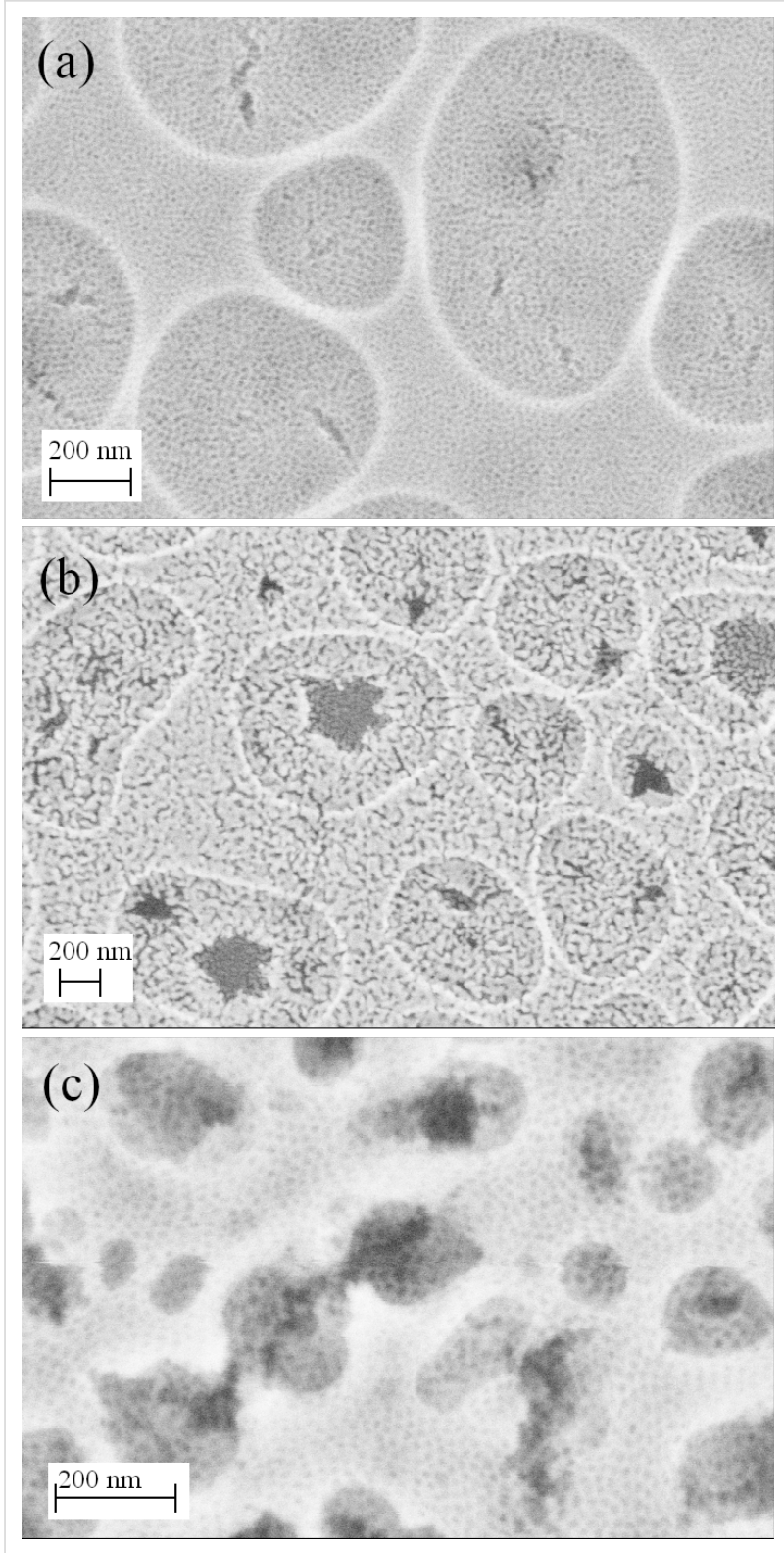

Figure 3: SEM surface morphologies of a mesoporous KLE-templated $\mathrm{MgTa}_{2} \mathrm{O}_{6}$ film after thermal treatment at (a) $760^{\circ} \mathrm{C}$ and (b) $1100^{\circ} \mathrm{C}$, and (c) of a mesoporous PIB6000-templated $\mathrm{MgTa}_{2} \mathrm{O}_{6}$ film after thermal treatment at $760{ }^{\circ} \mathrm{C}$.

thermal stability. This property was attributed to the special templating properties of KLE, which forms relatively large micelles during the EISA procedure and hence helps to stabilize the ordered mesopores even after the template has been removed [15-19]. In addition, the randomly distributed round concaves also possibly aid the release of thermal stress, thus helping to maintain the ordered mesopores up to calcination temperatures as high as $1000{ }^{\circ} \mathrm{C}$.

2-D-SAXS patterns of the as-stabilized mesoporous $\mathrm{MgTa}_{2} \mathrm{O}_{6}$ film and of those heated to 550,650 and $760{ }^{\circ} \mathrm{C}$ are shown in 
(a)

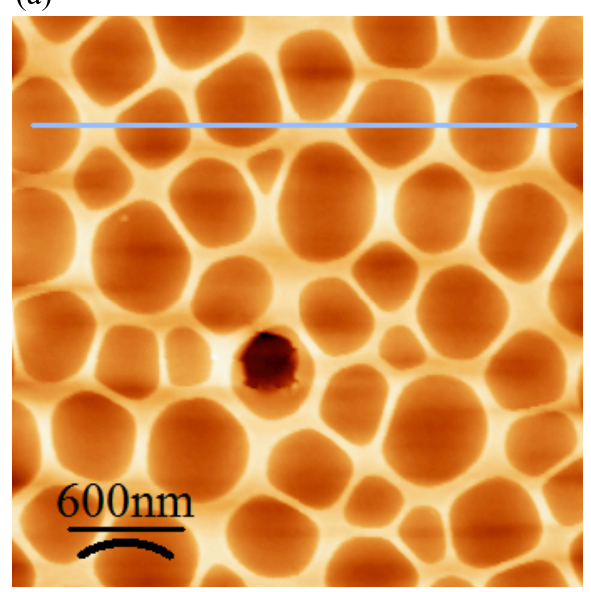

(c)

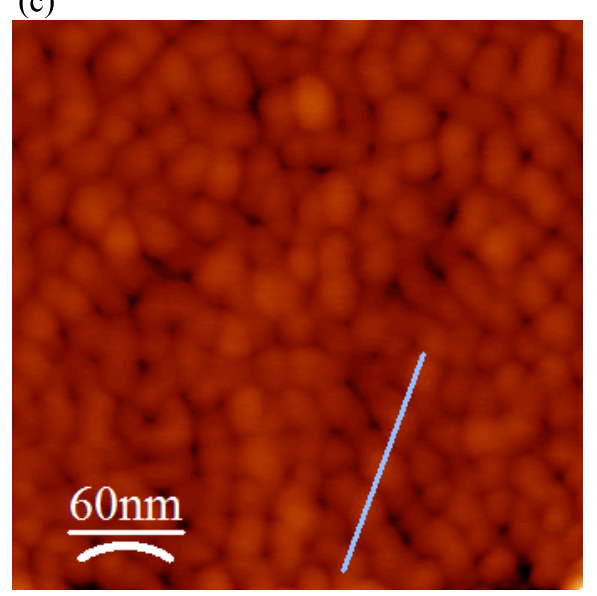

(b)

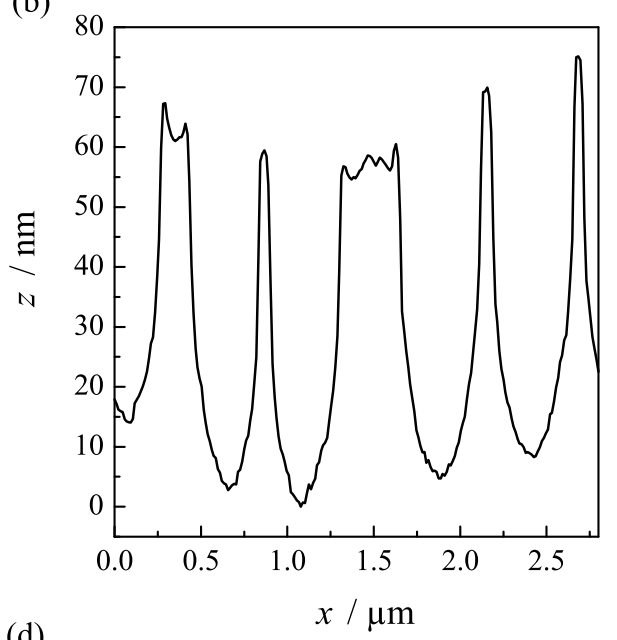

(d)

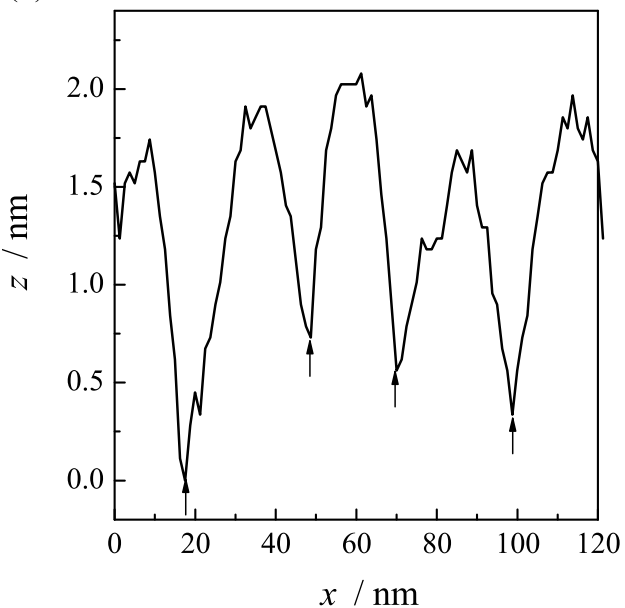

Figure 4: $\operatorname{AFM~(a,~c)~morphology~of~the~KLE-templated~mesoporous~} \mathrm{MgTa}_{2} \mathrm{O}_{6}$ film after calcination at $760{ }^{\circ} \mathrm{C}$. The corresponding profiles along the lines indicated in (a) and (c) are shown in (b) and (d), respectively.
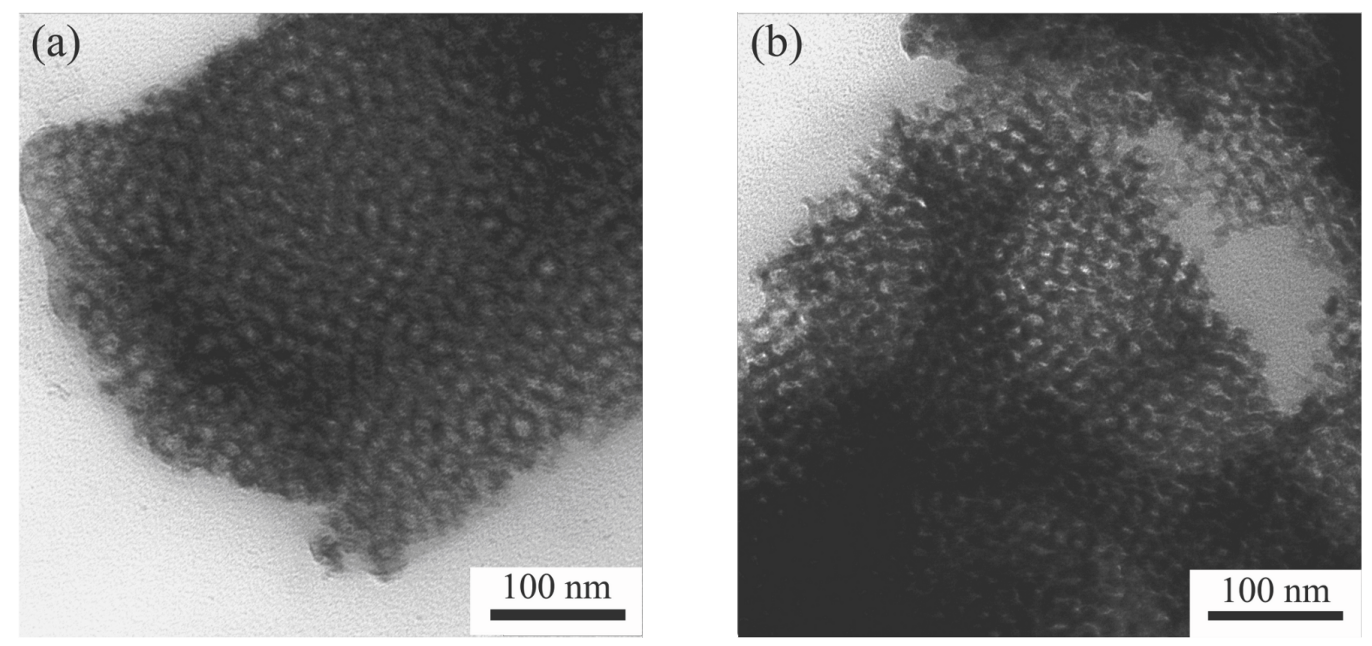

Figure 5: TEM morphology of a fragment scratched off from a mesoporous KLE-templated $\mathrm{MgTa}_{2} \mathrm{O}_{6}$ thin film before (a) and after calcination at $760^{\circ} \mathrm{C}(\mathrm{b})$. 


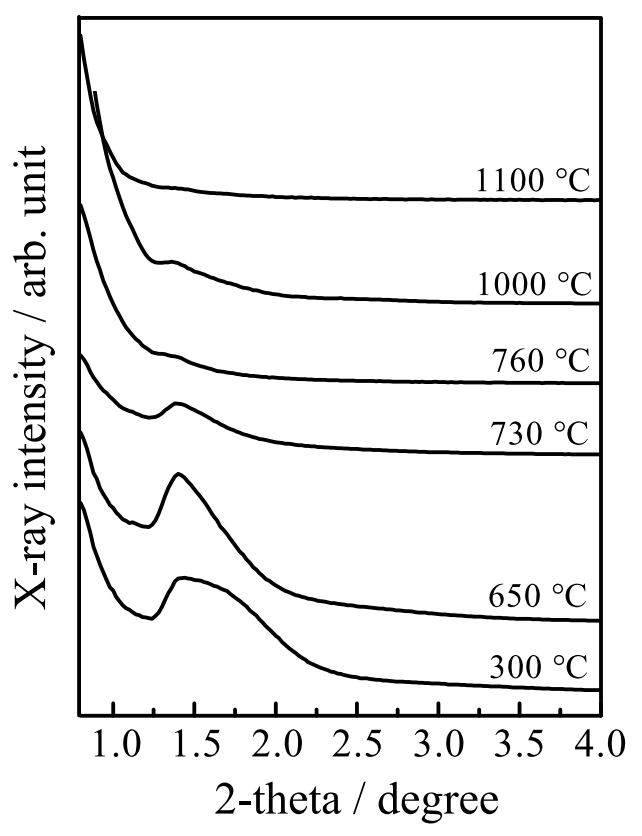

Figure 6: SAXS patterns (measured in symmetric reflection) of the mesoporous $\mathrm{KLE}$-templated $\mathrm{MgTa}_{2} \mathrm{O}_{6}$ thin film after calcination at various temperatures.

Figure 7. Here, the material was synthesized on ultrathin $\mathrm{Si}$ wafers (thickness ca. $30 \mu \mathrm{m}$ ), allowing the penetration of the covered wafers by X-rays. The maxima attributable to a bcc mesostructure in [110] orientation relative to the substrate can be discerned in the 2-D patterns measured with an angle of incidence of $\beta=10^{\circ}$, even after the onset of crystallization [20]. In addition, the 2-D-SAXS patterns became increasingly ellip- soidal, suggesting an anisotropic shrinkage of the mesostructure in the direction normal to the substrate, which has often been observed previously [20]. For the SAXS patterns obtained in transmission geometry $\left(\beta=90^{\circ}\right)$ the $1,-1,0$ ring, corresponding to a random orientation of mesostructured domains of the bcc mesoporous structure within the plane parallel to the substrate, was observed for all the films. No in-plane contraction in the plane occurred even for a film heated to $760{ }^{\circ} \mathrm{C}$, which is in agreement with the crack-free surface observed by SEM (Figure 3) and AFM (Figure 4). The in-plane $d$-spacing of $22 \mathrm{~nm}$ derived from the 2-D-SAXS patterns collected at $\beta=90^{\circ}$ agreed well with the AFM measurement (Figure 4). 2-D-SAXS data of F127- and PIB6000-templated films are shown in Supporting Information File 1 (Figure S5).

The EISA procedure has been widely utilized to synthesize thin films with ordered mesopores, with the help of certain surfactants; however, such round concaves containing ordered mesopores have not been noticed before. As a preliminary result, we ascribe the formation of such a nanoarchitecture to the $\mathrm{Mg}^{2+}$ ions in the precursor, which increased the polarity of the ethanol and enhanced the evaporation speed of the solvent. The rapid evaporation produced randomly distributed bubbles, and when these collapsed they left randomly distributed, open, round concaves.

The mesoporosity was additionally investigated by nitrogen physisorption at $77 \mathrm{~K}$ (see Supporting Information File 1). Since the amount of material is by far too small for a single film, as an example, four films of PIB6000-templated $\mathrm{MgTa}_{2} \mathrm{O}_{6}$ were deposited on top of each other in order to provide a suffi-
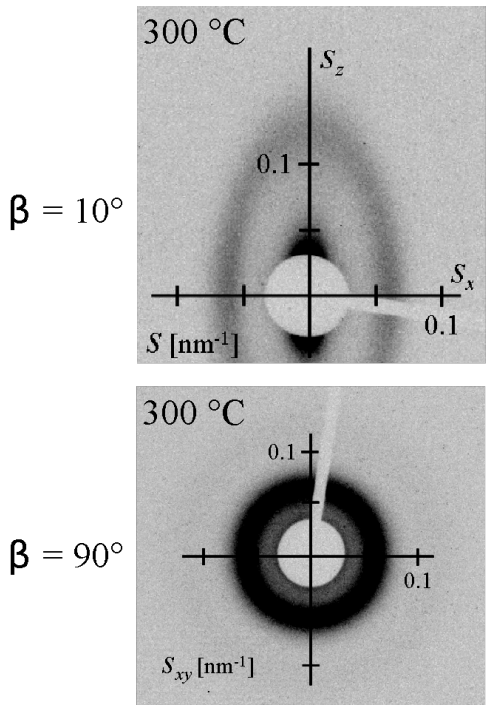
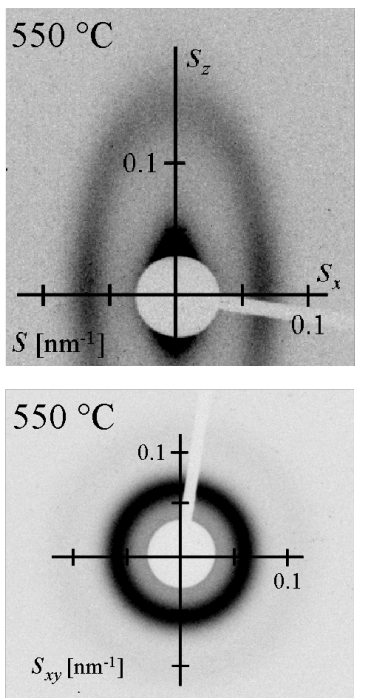
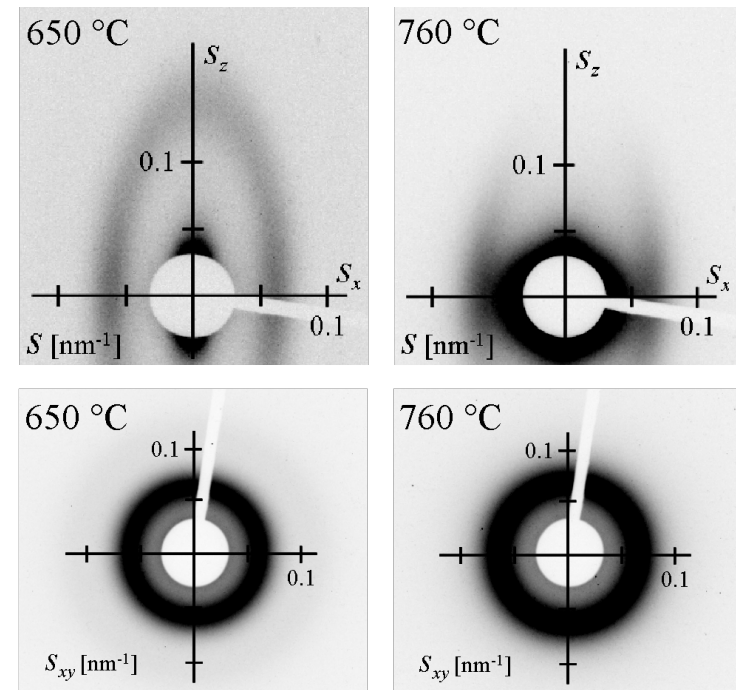

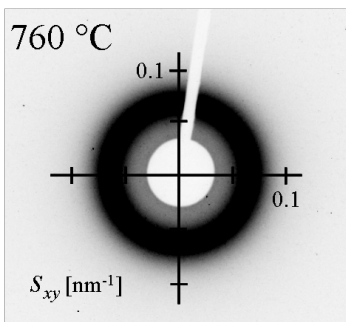

Figure 7: 2-D-SAXS patterns of the KLE-templated mesoporous $\mathrm{MgTa}_{2} \mathrm{O}_{6}$ thin film after calcination at various temperatures. The values $\beta=10^{\circ}$ and $\beta=90^{\circ}$ indicate the angles of incidence between the surface of the film and the $X$-ray beam. 

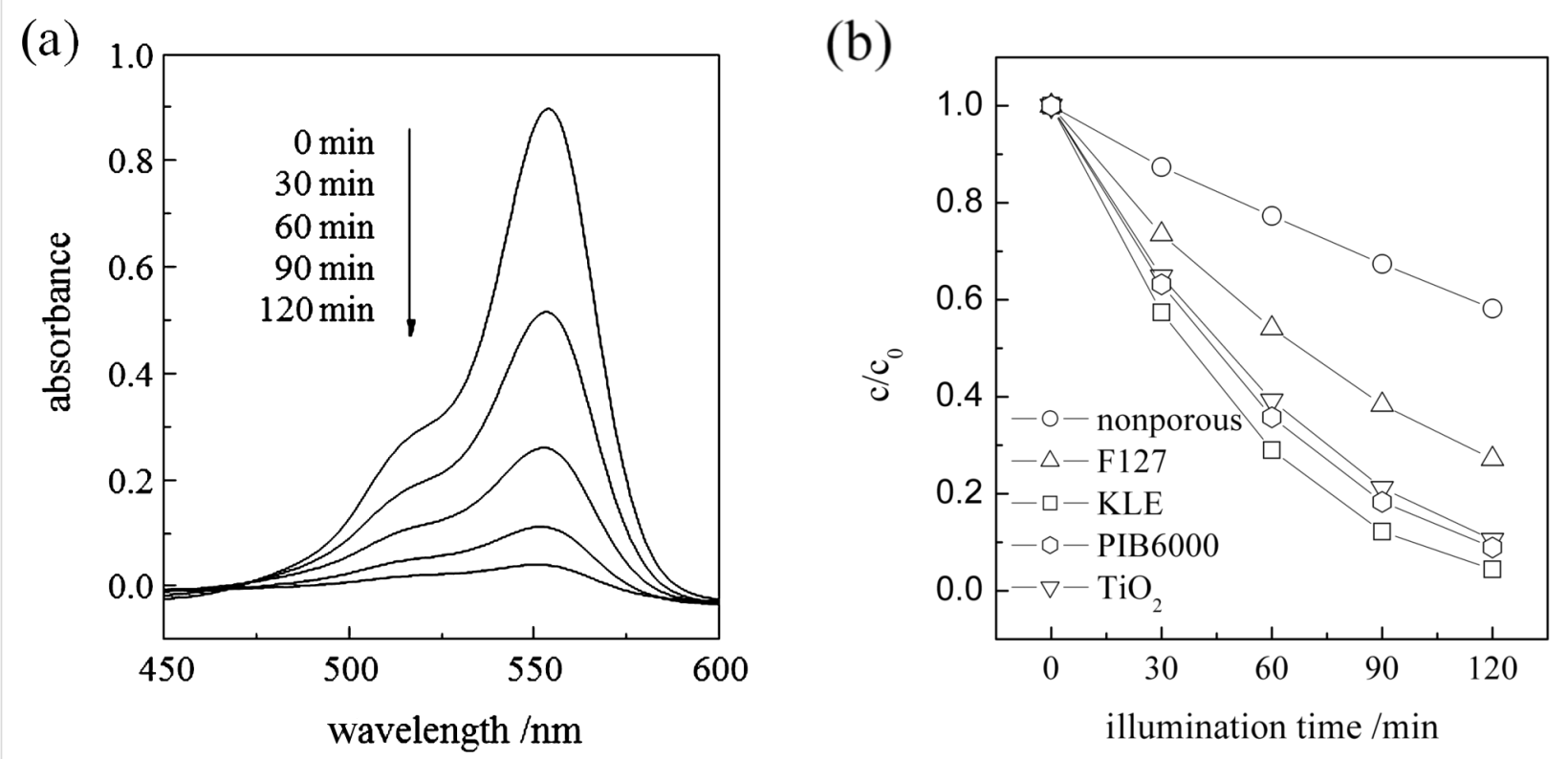

Figure 8: (a) Absorption spectra of $\mathrm{RhB}$ after photodegradation for given durations, assisted by the mesoporous $\mathrm{KLE}^{-t e m p l a t e d ~} \mathrm{MgTa}_{2} \mathrm{O}_{6}$ thin film after calcination at $790^{\circ} \mathrm{C}$. (b) The $\mathrm{RhB}$ concentration as a function of the photodegradation time, assisted by the mesoporous anatase $\mathrm{TiO}_{2}$ thin film $\left(\right.$ “ $\mathrm{TiO}_{2}$ ") after calcination at $550{ }^{\circ} \mathrm{C}$, the $\mathrm{KLE}$-, $\mathrm{PIB} 6000$ - and $\mathrm{F} 127$-templated mesoporous $\mathrm{MgTa}_{2} \mathrm{O}_{6}$ thin film after calcination at $790{ }^{\circ} \mathrm{C}$, as well as the nonporous $\mathrm{MgTa}_{2} \mathrm{O}_{6}$ thin film.

ciently large absolute surface area. These multilayer films were studied by SAXS and SEM to ensure that indeed the multilayer deposition did not disturb the mesostructure. For comparison, multilayers of nontemplated films were studied by nitrogen physisorption.

For such a PIB6000-templated mesoporous multilayer $\mathrm{MgTa}_{2} \mathrm{O}_{6}$ film with four single layers a BET surface area of ca. $260 \mathrm{~m}^{2} \mathrm{~cm}^{-3}$ was observed (after heat treatment at $790{ }^{\circ} \mathrm{C}$ ), which is typical of mesoporous films with such large mesopores. While the quality of the isotherm is limited, owing to the low amount of material, an average mesopore size of ca. $12 \mathrm{~nm}$ can be formally deduced from the BJH approach applied to the adsorption branch. Such a value has to be regarded with care, but nevertheless is consistent with the suggestion of the spherical mesopores being substantially contracted perpendicular to the surface. Thus, nitrogen physisorption provides a welldefined accessible mesopore structure up to high temperatures. A nontemplated film did not exhibit substantial uptake of nitrogen, and no reasonable isotherm was obtained.

\section{Photocatalytic activity evaluation}

In the absence of the oxide film, the UV irradiation induced no remarkable degradation of rhodamine $\mathrm{B}(\mathrm{RhB})$ in water. When the $\mathrm{MgTa}_{2} \mathrm{O}_{6}$ film was exposed to radiation, $\mathrm{RhB}$ underwent gradual decomposition depending on the irradiation time. As an example, Figure 8a shows the absorption curve of the aqueous $\mathrm{RhB}$ solution as a function of the UV irradiation time in the presence of the KLE-templated $\mathrm{MgTa}_{2} \mathrm{O}_{6}$ film after calcination at $790^{\circ} \mathrm{C}$. The change in $\mathrm{RhB}$ concentration as a function of the irradiation time, in the presence of various oxide films, is illustrated in Figure 8b. Here, two oxide films, namely, a mesoporous anatase film and a F127-templated $\mathrm{MgTa}_{2} \mathrm{O}_{6}$ film, were included as references. The fabrication and characterization of the mesoporous anatase film is reported elsewhere [21]. F127templated $\mathrm{MgTa}_{2} \mathrm{O}_{6}$ films also exhibited an ordered mesoporous structure with concaves, even after calcination at $760{ }^{\circ} \mathrm{C}$; however, the pore-to-pore distance was much smaller and the mesopores were less ordered compared to those templated by KLE. In addition, the round concaves were much smaller and distributed less homogeneously. After calcination, the F127-templated $\mathrm{MgTa}_{2} \mathrm{O}_{6}$ film exhibited XRD patterns corresponding to tri-rutile structure $\mathrm{MgTa}_{2} \mathrm{O}_{6}$ (see Figure $\mathrm{S} 1$ for the 2-D-SAXS patterns, Figure S2 for the SEM morphology, and Figure S3 for the XRD pattern in Supporting Information File 1). From Figure $8 \mathrm{~b}$ it can be seen that, of all the various oxide films, the KLE derived mesoporous $\mathrm{MgTa}_{2} \mathrm{O}_{6}$ film possessed the highest activity in assisting the photodegradation of $\mathrm{RhB}$ in water.

Interestingly, PIB6000-templated mesoporous $\mathrm{MgTa}_{2} \mathrm{O}_{6}$ thin film showed a very similar dye-degradation activity as compared with the KLE-templated films.

Photocatalytic degradation of RhB in water roughly follows a pseudo-first-order reaction [22-24], 


$$
\ln \frac{c_{0}}{c}=k t
$$

where $c / c_{0}$ is the normalized $\mathrm{RhB}$ concentration, $t$ is the illumination time, and $k$ is the apparent reaction rate in terms of $\min ^{-1}$. All of the data demonstrated good linearity for all the curves based on Equation 1 (Figure not shown). The derived reaction rate constant is listed in Table 1. Also included in Table 1 is the so-called turnover frequency (TOF), which defines the ratio of the reaction rate constant to the catalyst content and reflects the intrinsic activity per site of catalysis [25]. The catalyst content in the mesoporous film was calculated assuming a condensed film with a porosity of ca. $30 \%$ and a thickness of $200 \mathrm{~nm}$ (the densities of $\mathrm{MgTa}_{2} \mathrm{O}_{6}$ [1] and anatase $\mathrm{TiO}_{2}$ [24] are $7.2 \mathrm{~g} \mathrm{~cm}^{-3}$ and $3.8 \mathrm{~g} \mathrm{~cm}^{-3}$, respectively), which would overestimate the catalyst content and hence underestimate the TOF value for the mesoporous films. A detailed description of the result in Table 1 will be presented later.

Figure 9 shows the reaction rate constants of the mesoporous and nonporous $\mathrm{MgTa}_{2} \mathrm{O}_{6}$ films as a function of the calcination temperature. The photocatalytic activity of the nonporous film reached an optimum value of ca. $0.0175 \mathrm{~min}^{-1}$ after being heated to $950{ }^{\circ} \mathrm{C}$. However, the evolution in photocatalytic activity for the mesoporous $\mathrm{MgTa}_{2} \mathrm{O}_{6}$ film with increasing calcination temperatures was considerably more complicated. Between $550^{\circ} \mathrm{C}$ and $760{ }^{\circ} \mathrm{C}$ the photocatalytic activity initially increased to a maximum of $0.0216 \mathrm{~min}^{-1}$ at $700{ }^{\circ} \mathrm{C}$, but then decreased as the calcination temperature rose to $760{ }^{\circ} \mathrm{C}$. Interestingly, the photocatalytic activity increased again to a maximum of $0.0260 \mathrm{~min}^{-1}$ when the calcination temperature rose from $760{ }^{\circ} \mathrm{C}$ to $790{ }^{\circ} \mathrm{C}$. There was a dramatic drop in photocatalytic activity as the temperature increased to $850{ }^{\circ} \mathrm{C}$ followed by a gradual increase as the temperature rose to $1100{ }^{\circ} \mathrm{C}$.

Since this peculiar increase and decrease in the activity is one of the most relevant findings of the present study, the measure- ments were repeated three times. As the results were similar to PIB6000-templated films, Figure 9 shows only one of the films for KLE-templated $\mathrm{MgTa}_{2} \mathrm{O}_{6}$.

Under UV illumination, $\mathrm{MgTa}_{2} \mathrm{O}_{6}$ adsorbs photons with a wavelength shorter than ca. $278 \mathrm{~nm}$ and generates electron-hole pairs corresponding to its bandgap of ca. $4.4 \mathrm{eV}$ [10] (see Figure S4, Supporting Information File 1, for the UV-vis diffuse-reflectance spectrum). The photogenerated holes diffuse all the way to the surface where they oxidize the preadsorbed $\mathrm{RhB}$ molecules directly, or indirectly by forming hydroxyl radicals, which abstract $\mathrm{H}$ atoms from the organics on or near the semiconductor surface [26]. During subsequent calcination, three factors readily affecting the photocatalytic activity

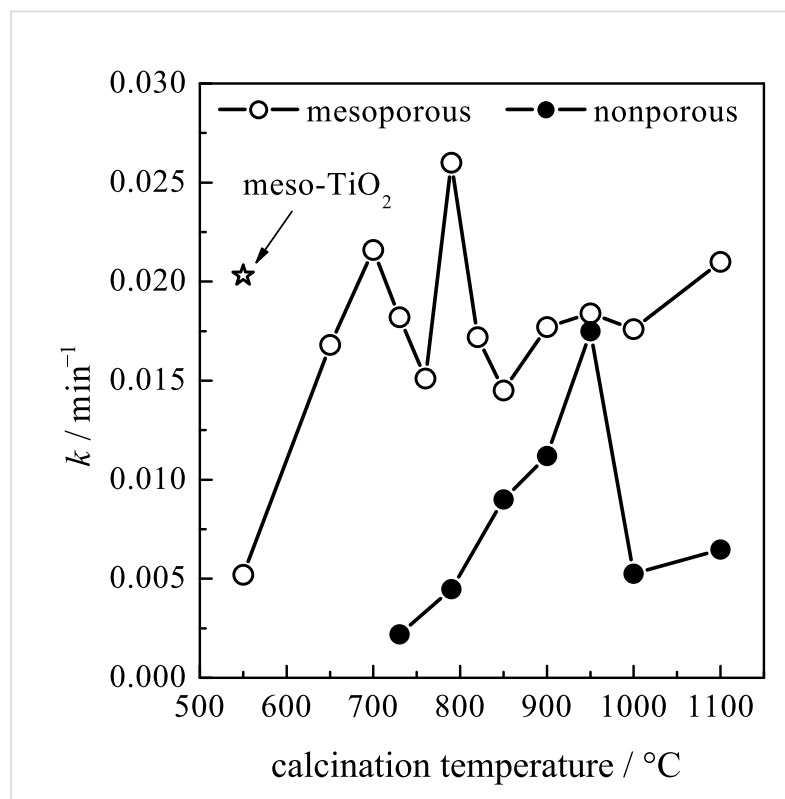

Figure 9: Reaction rate constants of the photodegradation reaction in the presence of the KLE-templated mesoporous and nonporous $\mathrm{MgTa}_{2} \mathrm{O}_{6}$ thin films after thermal treatment at various temperatures. The value for a mesoporous $\mathrm{TiO}_{2}$ thin film is represented by a star in the figure for reference.

Table 1: Reaction rate constant $(k)$ and turnover frequency (TOF) of selected photocatalysts.

\begin{tabular}{|c|c|c|c|}
\hline photocatalyst & $m$ (catalyst content) / mmol & $k / \min ^{-1}$ & $\operatorname{TOF}(\mathrm{k} / \mathrm{m}) /(\mathrm{mmol} \cdot \mathrm{min})^{-1}$ \\
\hline nonporous $\mathrm{MgTa}_{2} \mathrm{O}_{6}$ film $\left(790{ }^{\circ} \mathrm{C}\right)$ & 0.00490 & 0.00448 & 0.914 \\
\hline nonporous $\mathrm{MgTa}_{2} \mathrm{O}_{6}$ film $\left(950^{\circ} \mathrm{C}\right)$ & 0.00490 & 0.0175 & 3.57 \\
\hline KLE-derived $\mathrm{MgTa}_{2} \mathrm{O}_{6}$ film $\left(790{ }^{\circ} \mathrm{C}\right)$ & 0.00490 & 0.0260 & 5.30 \\
\hline F127-derived $\mathrm{MgTa}_{2} \mathrm{O}_{6}$ film $\left(790^{\circ} \mathrm{C}\right)$ & 0.00490 & 0.0109 & 2.22 \\
\hline PIB-derived $\mathrm{MgTa}_{2} \mathrm{O}_{6}$ film $\left(790^{\circ} \mathrm{C}\right)$ & 0.00490 & 0.0202 & 4.12 \\
\hline mesoporous $\mathrm{TiO}_{2}$ film $\left(550{ }^{\circ} \mathrm{C}\right)$ & 0.0152 & 0.0203 & 1.34 \\
\hline
\end{tabular}


changed dramatically in the current investigation, i.e., crystallinity, grain size, and ordered mesopores [27,28]. Defects serve as traps for photogenerated electron-hole pairs [26]; therefore, improved crystallinity prolongs the lifetime of the photogenerated pairs, thus increasing the number of holes that are able to diffuse all the way to the surface to be involved in the photodegradation reaction. Small grains are assumed to facilitate the photocatalytic reaction, as it takes less time for the photogenerated pairs of holes and electrons to migrate all the way to the surface to be involved in the reaction, which thus inhibits the recombination of the pairs $[27,28]$. Ordered mesopores being accessible from the top favors the diffusion of organic molecules to the oxide surface and at the same time significantly increases the number of catalytically active sites [15]. In a word, improved crystallinity and small grain size of oxides, together with well-ordered mesopores contribute to the photocatalytic activity of semiconductor oxide films with ordered mesoporous structures.

Increasing the calcination temperatures promotes crystallinity, but at the same time causes grain growth and deterioration of the ordered mesoporous structure; consequently, choosing the calcination temperature is always a balancing act. Considering that $760{ }^{\circ} \mathrm{C}$ is the onset of crystallization for the present $\mathrm{MgTa}_{2} \mathrm{O}_{6}$ (Figure 1), the fact that the first maximum appeared at $700{ }^{\circ} \mathrm{C}$ in the temperature range of $550-760{ }^{\circ} \mathrm{C}$ for the mesoporous $\mathrm{MgTa}_{2} \mathrm{O}_{6}$ film can be attributed to the balancing act between the crystallinity and the ordered mesopores. When heated to a temperature tens of degrees below the onset of crystallization, e.g., $700^{\circ} \mathrm{C}$, the decay in the ordered mesopores was not so significant, as can be discerned from the SAXS results shown in Figure 6 and Figure 7. Therefore, the enhanced crystallinity obtained by increasing calcination temperature produced a near linear improvement in the photocatalytic activity at $700{ }^{\circ} \mathrm{C}$. As the calcination temperature approached that of the onset of crystallization, decay in the ordered mesoporous structure became significant due to the further mechanical stress accompanying the amorphous-crystalline phase transformation [29]. There was a decline in photocatalytic activity at the point where the advantages of the increasing crystallinity were outweighed by the disadvantage introduced by the deterioration of the ordered mesopores.

After the onset of crystallization, the negative effect caused by the collapsed mesoporous structure stabilized. In this case, one should expect the gradually increasing crystallinity to produce a gradual increase in photocatalytic activity as calcination temperatures rise. However, the other factor readily affecting the photocatalytic activity of a crystallized oxide, i.e., the grain size, should not be neglected. After the onset of crystallization, the grain size of $\mathrm{MgTa}_{2} \mathrm{O}_{6}$ increased steadily with increasing calcination temperature from $760{ }^{\circ} \mathrm{C}$ to $950{ }^{\circ} \mathrm{C}$, as indicated in Figure 2. The negative effect caused by larger grains, in combination with the positive effect originating from the improved crystallinity, resulted in the second maximum of photocatalytic activity at $790{ }^{\circ} \mathrm{C}$ in the temperature range of $760-850{ }^{\circ} \mathrm{C}$. The gradual increase in photocatalytic activity of the films after calcination beyond $850{ }^{\circ} \mathrm{C}$ can be ascribed to a consistently improved crystallinity and also to the fact that the changes in the grain size and mesopores were not overly significant.

The positive impact of the ordered mesoporous structure on the photocatalytic activity is reinforced by the significantly higher photocatalytic performance of the mesoporous $\mathrm{MgTa}_{2} \mathrm{O}_{6}$ film compared to the nonporous one (Figure 9). In addition, the KLE-templated mesoporous $\mathrm{MgTa}_{2} \mathrm{O}_{6}$ film exhibited higher photocatalytic activity than the F127-templated counterpart at the optimized calcination temperature of $790{ }^{\circ} \mathrm{C}$. In the current investigation, a $\mathrm{MgTa}_{2} \mathrm{O}_{6}$ film with an ordered mesoporous structure was also successfully synthesized by using the commercial F127 template even after calcination at $760{ }^{\circ} \mathrm{C}$; however, the mesopores were much smaller and less ordered. It is not possible to synthesize ordered mesoporous $\mathrm{MgTa}_{2} \mathrm{O}_{6}$ films with crystallized walls by using the other widely used block polymer of P123, because of the even smaller mesopores formed during the EISA procedure [11]. Therefore, the present KLE template contributes greatly to the $\mathrm{MgTa}_{2} \mathrm{O}_{6}$ film with microstructures favoring the photocatalytic property.

Besides the ordered mesoporous structure, the randomly distributed round concave areas with depths of ca. $60 \mathrm{~nm}$ might further contribute to the photocatalytic activity. Compared to the generally achieved ordered mesoporous structure with a smooth surface, such a 3-D nanoarchitecture enlarged the surface area of $\mathrm{MgTa}_{2} \mathrm{O}_{6}$ exposed to the $\mathrm{RhB}$ solution. Meanwhile, as evidenced from Figure 3, cracks that initiated during the calcination procedure, due either to the thermal mismatch between the $\mathrm{MgTa}_{2} \mathrm{O}_{6}$ film and the substrate or to the mechanical stress originating from the amorphous-crystalline transformation, were effectively confined within the round concaves, which improved the interfacial strength of the thin film.

The present nanoarchitectured mesoporous $\mathrm{MgTa}_{2} \mathrm{O}_{6}$ film possessed an optimized photocatalytic activity significantly higher than that of the ordered mesoporous anatase film. When considering the TOF value, the nanoarchitectured $\mathrm{MgTa}_{2} \mathrm{O}_{6}$ film calcinated at $790{ }^{\circ} \mathrm{C}$ possessed a photocatalytic activity ca. four times that of the mesoporous anatase film (Table 1). Although $\mathrm{MgTa}_{2} \mathrm{O}_{6}$ powders have been reported to possess the ability to assist photoinduced water-splitting, their activities are not promising $[10,11]$. The successful synthesis of the present novel nanoarchitectured $\mathrm{MgTa}_{2} \mathrm{O}_{6}$ film significantly promoted 
the potential property of $\mathrm{MgTa}_{2} \mathrm{O}_{6}$ as a photocatalyst, which we believe could find practical applications in heterogeneous photocatalysts and solar-induced water splitting.

\section{Conclusion}

Well-crystallized $\mathrm{MgTa}_{2} \mathrm{O}_{6}$ films with ordered mesoporous structures, imposed by randomly but homogeneously distributed round concaves, were synthesized through evaporationinduced self-assembly followed by calcination at temperatures above $760{ }^{\circ} \mathrm{C}$. Such an advanced mesostructure can be achieved by special block copolymers such as KLE or polymers of the poly(isobutylene)- $b$-poly(ethylene oxide) type, which show similar properties in terms of structure and photocatalysis (see Supporting Information File 1). With increasing calcination temperature up to $1100{ }^{\circ} \mathrm{C}$, two maxima in the photocatalytic activity for the $\mathrm{MgTa}_{2} \mathrm{O}_{6}$ film were achieved as a result of the combined effects of increasing crystallinity, increasing grain size, and deterioration of the ordered mesopores. The $\mathrm{MgTa}_{2} \mathrm{O}_{6}$ film with a novel nanoarchitecture possessed an enhanced ability to assist photodegradation of rhodamine B in water under UV irradiation. The optimal photocatalytic activity, when evaluated in terms of turnover frequency, was about four times that of previously reported anatase films with ordered mesopores [15] and even exceeded the photocatalytic performance of such films doped with other elements (see, e.g., [30] and references therein).

In conclusion, our work represents a show-case study regarding the interplay of crystallinity/crystallite size and mesoscopic order. The combination of photocatalytical characterization with comprehensive, temperature-dependent structural analysis proved that mesoporosity itself is not sufficient to endow metal oxides with advanced physicochemical performance.

\section{Experimental section}

\section{Film fabrication}

$\mathrm{MgCl}_{2}$ (47 mg; 99.99\%, Aldrich) and $\mathrm{Ta}\left(\mathrm{OC}_{2} \mathrm{H}_{5}\right)_{5}(500 \mathrm{mg}$; $99.98 \%$, Aldrich) were dissolved separately in ethanol (2 g) under magnetic stirring. After the addition of concentrated $\mathrm{HCl}$ (1.5 g) to the $\mathrm{Ta}\left(\mathrm{OC}_{2} \mathrm{H}_{5}\right)_{5}$ solution, the $\mathrm{MgCl}_{2}$ ethanolic solution was added dropwise. Finally, an isotropic solution consisting of the KLE template $(100 \mathrm{mg}$; or $100 \mathrm{mg}$ of the polymer F127 or PIB6000), ethanol (2 g) and tetrahydrofuran $(1 \mathrm{~g})$ was added, and the final precursor was stirred for a further $6-10 \mathrm{~h}$ before dip-coating. This amount of block copolymers was found to be optimum with respect to the mesostructural organization. The $\mathrm{MgTa}_{2} \mathrm{O}_{6}$ thin films were deposited on $\mathrm{Si}$ wafers by dip coating at a controlled relative humidity of $12 \%$ with a constant withdrawal speed of $6.5 \mathrm{~mm} \mathrm{~s}^{-1}$, and then dried at $80{ }^{\circ} \mathrm{C}$ for $1 \mathrm{~h}$ in air and maintained at $300{ }^{\circ} \mathrm{C}$ overnight in order to stabilize the mesoporous structure. The subsequent calcination was conducted by heating to the desired temperatures at a rate of $5 \mathrm{~K} \mathrm{~min}^{-1}$. The samples were then removed immediately and allowed to cool down rapidly. The nonporous $\mathrm{MgTa}_{2} \mathrm{O}_{6}$ film was fabricated in a similar procedure except that no template was added in the precursor.

\section{Film characterization}

Scanning electron microscopy (SEM) observations were performed in a LEO440 instrument with an acceleration voltage of $3.0 \mathrm{kV}$. Atomic force microscopy (AFM) investigations were conducted with a Nanoscope III, Digital Instruments, in tapping mode. Transmission electron microscopy (TEM) images were taken with a Zeiss EM $912 \Omega$ instrument at an acceleration voltage of $120 \mathrm{kV}$. The small-angle X-ray scattering (SAXS) and X-ray diffraction (XRD) measurements were performed in a Bruker D8 diffractometer with an accelerating voltage of $40 \mathrm{kV}$ and a current of $40 \mathrm{~mA}$, with $\mathrm{Cu} \mathrm{K}_{\alpha}$ radiation. The 2-DSAXS measurements were carried out by using a Nonius rotating anode setup $\left(\mathrm{Cu} \mathrm{K} \mathrm{K}_{\alpha}\right.$ radiation with $\left.\lambda=0.154 \mathrm{~nm}\right)$ featuring a three-pinhole collimation system and a MAR CCD area detector, with a sample-to-detector distance of $750 \mathrm{~mm}$. The angle $\beta$ between the incident beam and the substrate was set to $10^{\circ}$ or $90^{\circ}$. Ultrathin Si wafers with a thickness of ca. $30 \mu \mathrm{m}$ were used for the 2-D-SAXS measurement.

\section{Photocatalytic activity measurement}

Rhodamine B (RhB), a xanthene dye molecule, was used as a probe to evaluate the photocatalytic activity of the thin films [22]. For each test, $33 \mathrm{~mL} \mathrm{RhB}$ aqueous solution with an initial concentration of $0.01 \mathrm{mmol} \mathrm{L}^{-1}$ was illuminated with an $8 \mathrm{~W}$ UV lamp ( $\lambda_{\max }=254 \mathrm{~nm}$, CAMAG, Germany) in the presence of the thin films with a total exposure surface area of ca. $16 \mathrm{~cm}^{2}$. The distance between the lamp and the film was ca. $2 \mathrm{~cm}$. The solution was stirred continuously and exposed to air during each run of the photocatalytic reaction for up to $120 \mathrm{~min}$, interrupted at an interval of $30 \mathrm{~min}$ to monitor the change in $\mathrm{RhB}$ concentration. The relative concentration $c / c_{0}$ of $\mathrm{RhB}$ was determined by normalizing the absorption of the solution to that of the initial one $\left(A / A_{0}\right)$ after a given reaction duration. Monitoring was conducted with a UV-vis spectrophotometer (UVIKON 931, Kontron Instruments, Switzerland) at a fixed wavelength of $554 \mathrm{~nm}$, using a quartz cuvette of $1 \mathrm{~cm}$ as the optical path length.

\section{Supporting Information}

\section{Supporting Information File 1}

Additional Figures.

[http://www.beilstein-journals.org/bjnano/content/

supplementary/2190-4286-3-13-S1.pdf] 


\section{Acknowledgements}

J.-M. Wu appreciates the research fellowship awarded by the Alexander von Humboldt Foundation. Prof. Antonietti and MPI of Colloids and Interfaces are thanked for hosting J.-M. Wu and for scientific support for this study.

BASF SE (especially Dr. Cornelia Röger) is gratefully acknowledged for providing the PIB-PEO block copolymer.

\section{References}

1. Ferrari, C. R.; Hernandes, A. C. J. Eur. Ceram. Soc. 2002, 22, 2101. doi:10.1016/S0955-2219(02)00020-1

2. Tealdi, C.; Islam, M. S.; Malavasi, L.; Flor, G. J. Solid State Chem. 2004, 177, 4359. doi:10.1016/j.jssc.2004.06.055

3. Huang, C.-L.; Chiang, K.-H.; Huang, C.-Y. Mater. Chem. Phys. 2005, 90, 373. doi:10.1016/j.matchemphys.2004.10.037

4. Kim, E. S.; Kim, S. J.; Lee, H. G. J. Ceram. Soc. Jpn. 2008, 116, 545. doi:10.2109/jcersj2.116.545

5. Sun, D. C.; Senz, S.; Hesse, D. J. Eur. Ceram. Soc. 2004, 24, 2453. doi:10.1016/j.jeurceramsoc.2003.07.004

6. Navale, S. C.; Samuel, V.; Ravi, V. Mater. Lett. 2005, 59, 3926. doi:10.1016/j.matlet.2005.07.035

7. Navale, S. C.; Ravi, V. Mater. Sci. Eng., B 2005, 119, 189. doi:10.1016/j.mseb.2005.02.058

8. Mergen, A. Ceram. Int. 2009, 35, 1151. doi:10.1016/j.ceramint.2008.05.016

9. Ganguli, A. K.; Nangia, S.; Thirumal, M.; Gai, P. L. J. Chem. Sci. 2006, 118, 37. doi:10.1007/BF02708763

10. Kato, H.; Kudo, A. Chem. Phys. Lett. 1998, 295, 487. doi:10.1016/S0009-2614(98)01001-X

11. Kondo, J. N.; Uchida, M.; Nakajima, K.; Daling, L.; Hara, M.; Domen, K. Chem. Mater. 2004, 16, 4304. doi:10.1021/cm030355s

12. Smarsly, B.; Grosso, D.; Brezesinski, T.; Pinna, N.; Boissière, C.; Antonietti, M.; Sanchez, C. Chem. Mater. 2004, 16, 2948. doi:10.1021/cm0495966

13. Grosso, D.; Boissière, C.; Smarsly, B.; Brezesinski, T.; Pinna, N.; Albouy, P. A.; Amenitsch, H.; Antonietti, M.; Sanchez, C. Nat. Mater. 2004, 3, 787. doi:10.1038/nmat1206

14. Wang, Y.; Brezesinski, T.; Antonietti, M.; Smarsly, B. ACS Nano 2009, 3, 1373. doi:10.1021/nn900108x

15. Beyers, E.; Cool, P.; Vansant, E. F. J. Phys. Chem. B 2005, 109, 10081. doi:10.1021/jp050310+

16. Sakatani, Y.; Grosso, D.; Nicole, L.; Boissiere, C.; Soler-Illia, G. J. de A. A.; Sanchez, C. J. Mater. Chem. 2006, 16, 77. doi:10.1039/b512824m

17. Groenewolt, M.; Brezesinski, T.; Schlaad, H.; Antonietti, M.; Groh, P. W.; Iván, B. Adv. Mater. 2005, 17, 1158. doi:10.1002/adma.200401549

18. Smarsly, B.; Antonietti, M. Eur. J. Inorg. Chem. 2006, 6, 1111. doi:10.1002/ejic.200501003

19. Brezesinski, T.; Smarsly, B.; limura, K.-i; Grosso, D.; Boissiere, C.; Amenitsch, H.; Antonietti, M.; Sanchez, C. Small 2005, 1, 889. doi:10.1002/smll.200500024

20. Ruland, W.; Smarsly, B. M. J. Appl. Crystallogr. 2007, 40, 409. doi:10.1107/S0021889807010503

21. Wu, J.-M.; Antonietti, M.; Gross, S.; Bauer, M.; Smarsly, B. M. ChemPhysChem 2008, 9, 748. doi:10.1002/cphc.200700679
22. Zhang, L.; Yu, J. C. Chem. Commun. 2003, 2078. doi:10.1039/b306013f

23. Wu, J.-M.; Qi, B. J. Am. Ceram. Soc. 2008, 91, 3961. doi:10.1111/j.1551-2916.2008.02786.x

24. Wu, J.-M.; Zhang, T.-W.; Zeng, Y.-W.; Hayakawa, S.; Tsuru, K.; Osaka, A. Langmuir 2005, 21, 6995. doi:10.1021/la0500272

25. Alvaro, M.; Aprile, C.; Benitez, M.; Carbonell, E.; Garcia, H. J. Phys. Chem. B 2006, 110, 6661. doi:10.1021/jp0573240

26. Linsebigler, A. L.; Lu, G.; Yates, J. T. Chem. Rev. 1995, 95, 735. doi:10.1021/cr00035a013

27. Carp, O.; Huisman, C. L.; Reller, A. Prog. Solid State Chem. 2004, 32, 33. doi:10.1016/j.progsolidstchem.2004.08.001

28. Wu, J.-M.; Huang, B.; Zeng, Y.-H. Thin Solid Films 2006, 497, 292. doi:10.1016/j.tsf.2005.10.066

29. Brezesinski, T.; Groenewolt, M.; Antonietti, M.; Smarsly, B. Angew. Chem., Int. Ed. 2006, 45, 781. doi:10.1002/anie.200502332

30. Zhao, J.; Sallard, S.; Smarsly, B. M.; Gross, S.; Bertino, M.; Boissière, C.; Chen, H.; Shi, J. J. Mater. Chem. 2010, 20, 2831. doi:10.1039/b919536j

\section{License and Terms}

This is an Open Access article under the terms of the Creative Commons Attribution License (http://creativecommons.org/licenses/by/2.0), which permits unrestricted use, distribution, and reproduction in any medium, provided the original work is properly cited.

The license is subject to the Beilstein Journal of Nanotechnology terms and conditions: (http://www.beilstein-journals.org/bjnano)

The definitive version of this article is the electronic one which can be found at: doi:10.3762/bjnano. 3.13 